Original article

\title{
Mental health status of Farmers in Maharashtra, India: A study from farmer suicide prone area of Vidarbha region
}

\author{
Priyanka Bomble*, Hemkhothang Lhungdim \\ International Institute for Population Sciences, Govandi Station Road, Deonar, Mumbai, Maharashtra, 400088, India
}

\section{A R T I C L E I N F O}

\section{Keywords:}

Farmers

Mental health

Suicides

Land

Widows

\begin{abstract}
A B S T R A C T
Background: In India according to the National Crime Records Bureau (NCRB) data 1, 31,666 people committed suicide and out of this 12,360 were farmers committed in 2014. When the suicide rate increases in a particular group in society, it is often an indicator that there are factors in the general environment which are placing selective pressure on the group in question. The present study examines the mental health status of Farmers in Maharashtra, India.

Methods: The cross-sectional study design was adopted to conduct this study. Three hundred (300) Household were selected for this study. The sample size was distributed proportionately in each village using Probability Proportional to size (PPS) sampling method. Households were stratified based on the loan amount to ensure that all types of borrower-farmers were included in the sample. The loan amounts were classified into three categories: up to Rs. 30,000 , Rs. 31,000 to Rs. 60,000, and more than Rs. 60,000. Univariate, Bivariate and logistic regression analysis have been conducted.

Results: More than half 58\%of farmers have reported distress of mental health and $41.7 \%$ farmers were reported no distress of mental health in last two weeks. Mean of the mental health status of farmers is 0.58 , and standard deviation (SD) is 0.49 . The most commonly reported symptoms of mental health relate to anxiety and insomnia, with $55 \%$ of farmers suffering from this symptoms. The second highest ranking prevalence of symptoms is somatic problems (34.7\%).

Conclusion: The immediate clinical and non-clinical interventions should be initiated to mitigate the suicides among the farmers.
\end{abstract}

\section{Introduction}

Farmers and agricultural workers are uniquely amongst the main occupational groups that live and work almost exclusively in rural areas. It is therefore important to understand the nature of rural areas in the context of health and health care. ${ }^{1}$ In India according to the NCRB data 1, 31,666 people committed suicide and out of this 12,360 were farmers committed in 2014. When the suicide rate increases in a particular group in society, it is often an indicator that there are factors in the general environment which are placing selective pressure on the group in question. These factors vary in type from the economic (e.g. Continuous failure crop and debt), to the demographic (family structure) to the psychological (e.g. mental illness). ${ }^{2}$

Mental health problems and services are neglected issue in rural areas and particularly in farming community. Mental illness constitutes nearly one sixth of all health-related disorders. ${ }^{3}$ Changing life-style, frequent disruptions in income, crop failure, natural calamity (drought and flood), economic crisis, unemployment, lack of social support and increasing insecurity are the compounding factors of mental health problems among farmers in India. ${ }^{4}$ The suicide of farmers in different parts of India since the mid-1990s provides another illustration of the impact of financial insecurity on mental health. ${ }^{5-7}$ Globalization and the advent of multinational companies have also led to new competition for small-scale. farmers whose goods are no longer competitively priced, which added to numerous other problems such as substandard quality seeds and the lack of support from banks. ${ }^{8}$ The study found that personal health problem of the deceased was identified in $21 \%$ of the cases. From these, $26 \%$ (6 cases) were those with some mental health problem. Illness gets aggravated due to poor economic condition because it makes care seeking difficult. ${ }^{9}$

In many developing countries, indebtedness to loan sharks is a great source of stress and worry for the farmers. While there is no information available regarding rates of mental health conditions for the farm population, suicide rates of male farmers have been reported as $5.4 \%$ in

\footnotetext{
* Corresponding author.

E-mail addresses: priyankabomble05@gmail.com (P. Bomble), lhungdim.hem@iips.net (H. Lhungdim).
} 
Indian population. The rural population is usually at a distance from any modern mental health services. In India, more than fifty percent of the population is living in rural areas having only limited health infrastructure, medical expertise and man power resources and other health facilities therefore mental health issues would be on the increase in rural areas. Mental health problems and services are neglected issue in rural areas and particularly among the farming communities. Therefore, the study examined mental health problem among farmers using a standardized validated questionnaire. Further, study investigated farming characteristics and their association with mental health of farmers in Vidarbha region of Maharashtra.

\section{Methods}

\subsection{Study design}

Yavatmal district is one of the eleven districts of Vidarbha region of Maharashtra. The farmers low level of education attainment have kept most of them economically backwards in this district. The Climate of the district is characterised by hot summer and general dryness. More than $75 \%$ of rainfall in this zone is received in Kharif season; hence Kharif cropping system predominates in the region. Cotton and Soybean are two major crops grown, and the economy is predominantly agrobased.

The cross-sectional community based study was carried out in Yavatmal districts of Maharashtra. The Yavatmal district has highest farmer suicides rate in Maharashtra. The farmers engaged in farming at the Yavatmal district those who were possessed own or leased land and aged 20-59 were consider for the study.

\subsection{Sampling design and size}

Four (4) villages have been selected purposively in Kalamb Taluka (sub division of district) in the Yavatmal district, according to the available data on the farmer's suicides, the highest numbers of suicides that occurred in these villages. Three hundred (300) households were selected for this study. The sample size was distributed proportionately in each village using Probability Proportional to size (PPS) sampling method. Households were stratified based on the loan amount to ensure that all types of borrower-farmers were included in the sample. The loan amounts were classified into three categories: up to Rs. 30,000, Rs. 31,000 to Rs. 60,000 , and more than Rs. 60,000 . The three hundred households were distributed nearly equally in the three categories101 samples had borrowed up to Rs. 30000, 101 in the Rs. $31,000-60,000$ category, and 98 in the category of Rs. 60,000 and above. Information on the amounts borrowed were taken from a cooperative bank, and the sample respondents were randomly selected from this.

\subsection{Statistical analysis}

The data entry was performed with CSPro 6.0 software package. Analysis was done using SPSS - version 21. Appropriate, bivariate and multivariate statistical techniques were used. Mean, Pearson's chisquare tests (for observing the level of association between the predictors and dependent variables) were also conducted. Binary logistic regression was applied to find out determinants of various dependent variables. In order to understand the covariates affecting the mental health of the farmers, binary logistic regression analysis has been used. In regression dependent variable codes as ' 1 ' for occurrence of an event and ' 0 ' as non-occurrence of the event.

\subsection{Assessment of psychiatric morbidity}

To assess psychiatric morbidity of farmers and widows, we used the General Health Questionnaire-28 (GHQ-28), a commonly used questionnaire with proven validity and reliability; (Goldberg et al., 1979). It is one of the most widely used and validated questionnaires to screen for emotional distress and possible psychiatric morbidity, and also responses on their health state over the past two weeks. General Health Questionnaire 28 (GHQ-28) is a popular 28- item screening test that is derived from factor analysis of General Health Questionnaire. A factor analysis was conducted to identify the underlying variables that would eventually help to explain the correlation patterns within the variables of GHQ-28. In addition, the factor analysis was done to identify a small number of factors in a larger number of manifest variables. The questionnaire has 4 subscales of Somatic Symptoms, Anxiety and Insomnia, Social Dysfunction and Severe Depression with 7 questions in each subscale. The scores are calculated by using binary ( 0 0-1-1) score where Not at all, No more than usual score- 0, and Rather more than usual and Much more than usual score- 1, using this method any score above 4 indicates the presence of distress(Goldberg et al., 1988). In order to examine the structure of the general health questionnaire, initial principle component analysis was done after Varimax rotation with Kaiser Normalization of all data was performed. Internal consistency of the overall and subscale scores was assessed using the KOM and Bartlett's Test statistics. The questionnaire was translated into the Marathi language.

\subsection{Response variables}

Respondents who reported any symptoms of mental health in the past two weeks were considered as farmers mental distress. Any symptoms of mental health and as per the four symptoms of mental health three symptoms were also covered as response variables including Somatic Symptoms, Anxiety and Insomnia, and Severe Depression.

\subsection{Independent variables}

For the present study, age of the respondent, education, occupation, caste, type of family, standard of living, total size of land, per acre total expenditure, per acre net returns, institutional loan, and non-institutional loan were considered independent variables.

\section{Results}

Table 1 presents percentage distribution of farmers by socio-demographic characteristics. The farmer's mean age was 44.69. Around $21.7 \%$ of farmers were in 55-59 age group followed by $18 \%$ in of $45-49$ age group, $17.7 \%$ 40-44 age, $13 \% 35-39$ and 50-54 age $10 \% 30-34$ and $6 \%$ were $19-29$ age group. Around $94.7 \%$ of the farmers were currently married. Nearly $33.7 \%$ of farmers completed their secondary education followed by $22.7 \%$ of farmers who completed graduate and above. As per the occupation, the majority of the farmers (76\%) were engaged in agriculture, and $15 \%$ depended on agriculture and casual labour for their income. Otherwise, 8.3\% farmers in the study depended on agriculture and own business. When we look into the religion, the Hindu religion household dominates with $82.7 \%$ and $17.3 \%$ were nonhindu. Similarly, in caste, Other Backwards Classes (OBC) households constitute 78\% whereas Scheduled Caste (SC) and Scheduled Tribe (ST) were $15 \%$. More than half $(52 \%)$ of the farmers were lived in the nuclear family. Around $26.3 \%$ of farmers reported that 2 to 4 persons were dependent on them. A slightly higher $76.3 \%$ of farmers reported more than 4 person was dependent on them.

Table 2 presented agriculture characteristics of farmers, regarding the size of land, about $48 \%$ of farmers holding between 0 and 2 hector land so-called Marginal/small farmers and 31\% medium farmers holding between 2 and 5 hectors of land. Only 20\% of farmers (large farmers) owned more than five hectors of land. It's revealed that many (42.3) percent of the farmers have per acre total expenditure on three crop Rs. $21000-30000$, followed by $35 \%$ have up to Rs. 20000 and, 
Table 1

Socio-demographic characteristics of household head (farmers) in Yavatmal District, Maharashtra 2013-2014.

\begin{tabular}{|c|c|c|}
\hline & Percent & $\mathrm{N}$ \\
\hline Age (mean) & 44.69 & \\
\hline $19-29$ & 6.0 & 18 \\
\hline $30-34$ & 10.0 & 30 \\
\hline $35-39$ & 13.0 & 39 \\
\hline $40-44$ & 17.7 & 53 \\
\hline $45-49$ & 18.0 & 54 \\
\hline $50-54$ & 13.7 & 41 \\
\hline $55-59$ & 21.7 & 65 \\
\hline \multicolumn{3}{|l|}{ Marital status } \\
\hline Currently married & 94.7 & 284 \\
\hline Never married/Widower & 5.6 & 16 \\
\hline \multicolumn{3}{|l|}{ Education } \\
\hline Illiterate/Primary & 24.3 & 73 \\
\hline Secondary & 33.7 & 101 \\
\hline Higher Secondary & 19.3 & 58 \\
\hline Graduate and Above & 22.7 & 68 \\
\hline \multicolumn{3}{|l|}{ Occupation } \\
\hline Agriculture & 76.0 & 20 \\
\hline Agri. \& Employer & 15.0 & 45 \\
\hline Agri. \&Own Business & 8.3 & 25 \\
\hline \multicolumn{3}{|l|}{ Caste } \\
\hline Schedule caste/Schedule tribe & 15.0 & 45 \\
\hline Other backward class & 78.0 & 243 \\
\hline Others & 7.0 & 21 \\
\hline \multicolumn{3}{|l|}{ Religion } \\
\hline Hindu & 82.7 & 284 \\
\hline Non-Hindu & 17.3 & 52 \\
\hline \multicolumn{3}{|l|}{ Type of family } \\
\hline Nuclear Family & 52 & 156 \\
\hline Joint Family & 48 & 144 \\
\hline \multicolumn{3}{|l|}{ Number of dependent person } \\
\hline 2 to 4 person & 26.3 & 79 \\
\hline$>4$ person & 76.3 & 221 \\
\hline Total & 100 & 300 \\
\hline
\end{tabular}

Table 2

Agriculture characteristics of farmers in Yavatmal District, Maharashtra 2013-2014.

\begin{tabular}{lll}
\hline & Percent & N \\
\hline Size of land & & \\
Marginal/small farmers (0-2H) & 48.3 & 145 \\
Medium farmers $(<2-5 \mathrm{H})$ & 31.7 & 95 \\
Large farmers (above 5 H) & 20 & 60 \\
Per acre total expenditure on three crop & & \\
Up to 20000 & 35.3 & 106 \\
21000-30000 & 42.3 & 127 \\
More than 30000 & 22.3 & 67 \\
Per acre net returns & & \\
Negative returns $>10000$ & 25 & 75 \\
Negative returns $<10000$ & 28.3 & 85 \\
Up to 10000 & 26.3 & 79 \\
More than 10000 & 20.3 & 61 \\
Institutional loan (Rs.) & & \\
Less than 30000 & 33.7 & 101 \\
31000-60000 & 33.7 & 101 \\
More than 60000 & 32.7 & 98 \\
Non-institutional loan (Rs.) & & \\
Up to 25000 & 47.7 & 72 \\
$>$ 25000 & 52.4 & 79 \\
Total & 100 & 300 \\
\hline
\end{tabular}

$22 \%$ spent more than Rs. 30000 . In the case of per acre net returns shows that majority of the farmers reported that (28) percent negative returns $<10000$, and $26 \%$ of farmers received up to 10000 per acre net returns. It is observed from the table that out of 300 farmers who had borrowed loan from an institution, the equal number of farmers (33.7\%) were having less than Rs. 30000 , Rs. 31000 to Rs. 60000 and more than Rs. 60000 loan amount. It was also found that non-
Table 3

Prevalence of general mental health symptoms measured by GHQ- 28, among farmers in Yavatmal District, Maharashtra, 2013-2014.

\begin{tabular}{llll}
\hline Symptoms of mental health & Percent & N & Cronbach's Alpha \\
\hline Somatic symptoms & 34.7 & 104 & 0.886 \\
Anxiety and insomnia & 55.0 & 165 & 0.905 \\
Social dysfunction & 7.3 & 22 & 0.854 \\
Severe depression & 24.7 & 74 & 0.888 \\
Any symptoms & $\mathbf{5 8 . 3}$ & $\mathbf{1 7 5}$ & \\
Total & $\mathbf{1 0 0}$ & $\mathbf{3 0 0}$ & \\
\hline
\end{tabular}

institution loan, it was noticed that $47.7 \%$ farmers had outstanding loan up to Rs. 25000 , and $52.4 \%$ of farmers had loan amount in the range of more than Rs. 50000 .

Table 3 shows mental health status of farmers in Vidarbha region of Maharashtra. This section examines mental health status of farmers by using 28 questions related to the general mental health GHQ-28 scale. Based on this questions, result carried out that more than half $58 \%$ of farmers have reported distress of mental health in last two weeks. The most commonly reported symptoms of mental health relate to anxiety and insomnia, with $55 \%$ of farmers suffering from these symptoms. The second highest ranking prevalence of symptoms is somatic problems (34.7\%). Twenty-four percent of the farmers who were reported symptoms of severe depression and only $7.3 \%$ of the farmers reported social dysfunction symptom of mental health. Taking a threshold of an overall score of 4 or more indicate the presence of distress as per the GHQ-28.

Table 4 shows any mental health symptoms of farmers by socio economic characteristics. This section has shown symptom of mental

Table 4

Differential in general mental health problem (Any symptoms) of farmers by socio economic characteristics in Vidarbha region of Maharashtra, 2013-2014.

\begin{tabular}{|c|c|c|c|c|}
\hline \multirow{2}{*}{$\begin{array}{l}\text { Background } \\
\text { Characteristics }\end{array}$} & \multicolumn{4}{|c|}{ Mental health of farmers } \\
\hline & No symptoms & Any symptoms & $\mathrm{N}$ & P- Value $\left(\chi^{2}\right)$ \\
\hline Age & & & & $13.186^{* * *}$ \\
\hline $19-34$ & 64.6 & 35.4 & 145 & \\
\hline $35-49$ & 39.7 & 60.3 & 95 & \\
\hline $50-59$ & 34.0 & 66.0 & 60 & \\
\hline Education & & & & $14.539 * * *$ \\
\hline Illiterate/Primary & 24.7 & 75.3 & 73 & \\
\hline $\begin{array}{l}\text { Secondary/Higher } \\
\text { Secondary }\end{array}$ & 43.4 & 56.5 & 159 & \\
\hline Graduate \& above & 55.9 & 44.1 & 68 & \\
\hline Occupation & & & & 2.915 \\
\hline Agriculture & 44.3 & 55.7 & 230 & \\
\hline $\begin{array}{l}\text { Agri. \& Employer/ } \\
\text { Business }\end{array}$ & 32.9 & 67.1 & 70 & \\
\hline Caste & & & & $4.496^{*}$ \\
\hline $\begin{array}{l}\text { Scheduled Tribe \& } \\
\text { Scheduled Caste\& } \\
\text { Others }\end{array}$ & 30.3 & 69.7 & 66 & \\
\hline $\begin{array}{l}\text { Other Backward Class } \\
\text { Religion } 10.916^{* * *}\end{array}$ & 44.9 & 55.1 & 234 & \\
\hline Hindu & 46.0 & 54.0 & 248 & \\
\hline Non-Hindu & 21.2 & 78.8 & 58 & \\
\hline Type of family & & & & $3.516^{* *}$ \\
\hline Nuclear family & 36.5 & 63.5 & 156 & \\
\hline Joint family & 47.2 & 52.8 & 144 & \\
\hline $\begin{array}{l}\text { Number of dependent } \\
\text { person }\end{array}$ & & & & $13.639 * *$ \\
\hline 2 to 4 person & 51.9 & 48.1 & 79 & \\
\hline$>4$ person & 38.0 & 62.0 & 221 & \\
\hline Standard of living & & & & $28.005^{* * *}$ \\
\hline Poor & 26.0 & 74.0 & 100 & \\
\hline Middle & 37.0 & 63.0 & 100 & \\
\hline Rich & 62.0 & 38.0 & 100 & \\
\hline Total & 41.7 & 58.3 & 300 & \\
\hline
\end{tabular}

$\mathrm{Chi}^{2}$ significant level $* * *<0.01, * *<0.05, *<0.10$. 
health among farmer, there is a significant relationship between the socio-economic condition and psychological distress. It was found that mental distress is higher among older age farmers, i.e., 60.3\% 35-49 age and $66 \% 50-59$ age than the younger age of farmers 19-34, (35.4\%). In the case of education, mental distress is higher when farmers are illiterate and primary educated (75.3\%). Whereas, mental distress found to decrease with the increase the education level among farmers-who are completed secondary and higher secondary education $(56.5 \%)$ and graduate and above $44.1 \%$. With regards to occupation, we found that $67.1 \%$ of farmers doing mix occupation that is agriculture and labour or business had more distress compared to who are doing only agriculture $(55.7 \%)$. The farmers belonged to schedule tribe or schedule caste and other caste having $69.7 \%$ mental distress than other backwards class (OBC) (55.1\%). There is a relation between the type of family and mental distress. It's revealed that greatest $63.5 \%$ farmer was having mental distress who were belonging nuclear family than joint family $(52.8 \%)$. Although, the analysis found that mental distress is high among poor farmers (74\%) than middle farmers (63\%) and rich farmer $(38 \%)$. And we found that the chi-square value is significant in the type of family, a number of a person depended and standard of living.

Table 5 evident that logistic regression odds ratios of reported any mental distress of last two week. In the first model, the farming characteristics are considered; in the second model, the farmer's characteristics are added. In the third model, two sets of variables are taken into consideration. Result reveal that farmers who had cost between Rs. 21000-30000 are 0.53 times less likely to reported mental distress in the reference to farmer who had cost Rs. up to 20000 . The farmers who borrowed institutional loan more than 60000 are 0.53 times less likely to the reported mental health problem than references category. Further, the results also indicate a statistically significant association between mental distress of farmers and the non-institutional loan. The farmers were borrowing the amount more than 25000 are more likely to experience distress as compared in reference to up to 25000 (OR 2.87; 95\% CR 1.57-5.25). In the second model individuals characteristics are included. In this modal, it was found that with increase in farmers age the mental distress also increase and it indicate a statistically significant, they are 2 times more likely to reported mental stress with age 35-49 and 3 times more likely to experience distress with the age 50-59 among farmers than reference category. In the context of standard of living, the fact is that farmer who are rich are 0.66 times less likely to reported mental distress in the reference to farmer who belong to poor category. In third model, the farming characteristics and individual's characteristics were taken into considerations, non-institutional loan, farmer's age, religion and standard of living had same significance as in model one and two. In addition, farmers who were

Table 5

Result of binary logistic regression analysis showing any symptoms of mental health by some selected background characteristics among farmers in Vidarbha region, Maharashtra, 2013-2014.

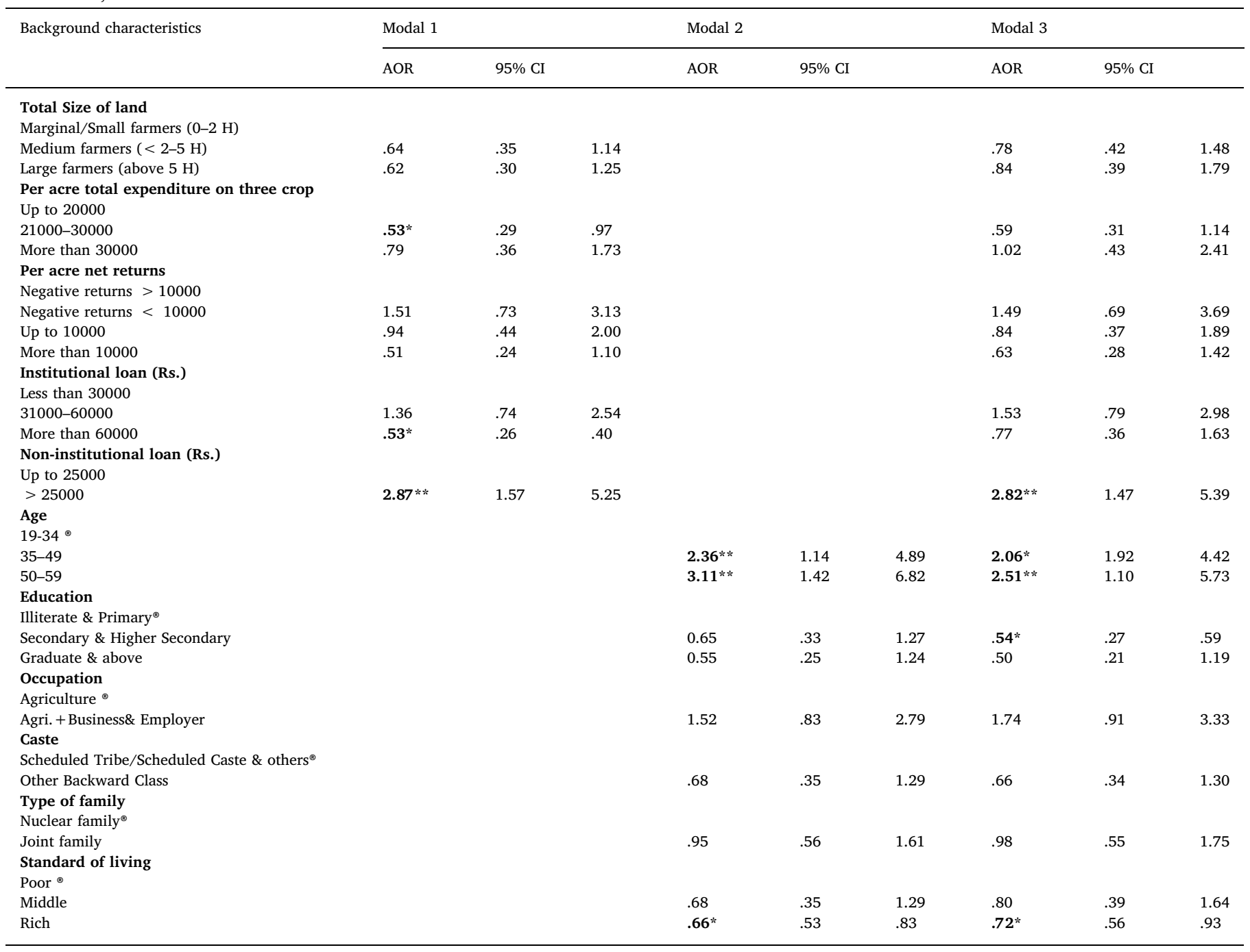

๑: Reference category; ${ }^{* * *} \mathrm{P}<0.01 ;{ }^{* *} \mathrm{P}<0.05 ;{ }^{*} \mathrm{P}<0.1$. 
completed secondary and higher secondary education are 0.54 times less likely to experience mental stress than reference category.

\section{Discussion}

In India there is abundant literature focusing on economic and political aspect for farmers suicide while the mental health aspects are very less taken into consider. Therefore the present study identify the mental health among farmers, for analyzing mental health of farmers used general health questionnaire (GHQ-28). The study finding indicated that more than half (58\%) of farmers are suffering from the psychological health problem. There is a high prevalence of psychological problems including anxiety and insomnia, somatic symptom, severe depression and social dysfunction in the farmer. A study on farmers households suggested that farmers faced psychiatric problem and it is significant risk factors for farmers suicide. ${ }^{10}$ Before the suicide victim had the behavior changes that is observed by the victim family.

Stressful life event were strongest contributor for developing mental problems experiencing by farmers. The analysis revealed that poor socio-economic factors, size of land, labour shortage, climate condition, nuclear type of families, poor return from cultivation, institutional loan and non-institutional loan as a significant predictor of mental distress among farmers. Similarly a past study on psychological autopsy for causes of farmers suicide. Previous studies found that the socio-economic factors are contributing stress and worry among farmers and finally suicide happened. ${ }^{11,12}$ Another study highlights that farmers experience different stress as due to illiteracy, large families, laboure management, government regulation and corruption, loan repayment to bank and moneylender. ${ }^{13}$ There is association between decline income flow and general mental disorder. The current study evident that the farmers borrow loan from both institutional and non-institutional sources are more likely to suffer from somatic symptom, anxiety and insomnia and severe depression symptom of mental health. Several studies identified indebtedness as the major factor associated with farmer suicides. ${ }^{14,15}$

\subsection{Limitation}

The study has few limitations to report. The study has been conducted in Yavatmal district which is known for higher rates of farmer's suicides. Hence, results of this study may not generalized to other settings. The study collected quantitative data, having some qualitative data to compliment the quantitative data could have produced more impact.

\section{Conclusion}

The present study determined the psychological health of the farmers by using GHQ-28 questioner. From the analysis it found that farmers were experiencing mental distress and suffering from psychological morbidity. There is a high prevalence of psychological problems including anxiety and insomnia, somatic symptom, and severe depression among the farmer. Farming is recognized as a high-stress occupation because the large proportion of farmers is psychologically unhealthy due to changes in farming practice and economic factors. There is a significant relationship between the socio-economic condition and psychological distress among farmers.

\section{References}

1. Gregoire A. The mental health of farmers. Occup Med. 2002;52(8):471-476 1.

2. Cavanagh JT, Carson AJ, Sharpe M, Lawrie SM. Psychological autopsy studies of suicide: a systematic review. Psychol Med. 2003;33(3):395-405.

3. Das A. Farmers' suicide in India: implications for public mental health. Int J Soc Psychiatry. 2011;57(1):21-29.

4. Chatterjee P. Economic crisis highlights mental health issues in India. The Lancet. 2009 4;373(9670):1160-1161.

5. Sundar M. Suicide in farmers in India. Br J Psychiatry. 1999;175(6):585-586.

6. Mohanty BB. 'We are like the living dead': farmer suicides in Maharashtra, western India. J Peasant Stud. 2005;32(2):243-276.

7. McCurdy SA, Carroll DJ. Agricultural injury. Am J Ind Med. 2000;38(4):463-480.

8. Patel V. Social origins, biological treatments: the public health implications of common mental disorders in India. Indian J Psychiatr. 2005;47(1):15.

9. Mishra S. Farmers' suicides in Maharashtra. Econ Pol Wkly. 2006;22:1538-1545.

10. Torske MO, Hilt B, Glasscock D, Lundqvist P, Krokstad S. Anxiety and depression symptoms among farmers: the HUNT study, Norway. J Agromed. 2016;21(1):24-33.

11. Behere PB, Behere AP. Farmers' suicide in Vidarbha region of Maharashtra state: a myth or reality? Indian J Psychiatr. 2008;50(2):124.

12. Dongre AR, Deshmukh PR. Farmers' suicides in the Vidarbha region of Maharashtra, India: a qualitative exploration of their causes. J Inj Violence Res. 2012;4(1):2.

13. Pande S, Savenije HH. A sociohydrological model for smallholder farmers in Maharashtra, India. Water Resour Res. 2016;52(3):1923-1947.

14. Merriott D. Factors associated with the farmer suicide crisis in India. J Epidemiol Glob Health. 2016;6(4):217-227.

15. Chindarkar N. A comparative analysis of farmers' suicides in Andhra Pradesh, India. Methodol Innov Online. 2007;2(2):6-19. 